\title{
No Effect of Morphine on Ventral Tegmental Dopamine Neurons during Withdrawal
}

\author{
François Georges, ${ }^{1}$ Catherine Le Moine,${ }^{1}$ and Gary Aston-Jones ${ }^{2}$ \\ ${ }^{1}$ Centre National de la Recherche Scientifique, Unité Mixte de Recherche 5541 “Interactions Neuronales et Comportements," Université Victor Segalen, \\ 33076 Bordeaux Cedex, France, and ${ }^{2}$ Laboratory for Neuromodulation and Behavior, Department of Psychiatry, University of Pennsylvania School of \\ Medicine, Translational Research Laboratories, Philadelphia, Pennsylvania 19104-3403
}

\begin{abstract}
Substantial evidence indicates that the ventral tegmental area (VTA) of the mesocorticolimbic dopaminergic (DA) system has a key role in mechanisms of opiate dependence. Although DA neurons have been studied extensively, little is known about their activity and their response to acute morphine during morphine dependence. We recorded the activity of VTA DA neurons in five groups of anesthetized rats: drug-naive (naive) rats, morphine-dependent [(MD) implanted with pellets] rats, and three groups of withdrawn rats. Withdrawals either were precipitated by naltrexone or occurred spontaneously $24 \mathrm{~h}$ or $15 \mathrm{~d}$ after pellet removal. We confirmed that acute morphine in naive rats produced a marked increase in the firing of VTA DA neurons. We also found that the basal firing rate of VTA DA neurons was markedly higher in MD than in naive rats; however, in MD rats, acute morphine failed to increase DA activity. We confirmed inhibition of VTA DA activity in MD rats in response to precipitated withdrawal; however, this inhibition resulted only in a normalization of the firing rate to that of naive animals. In rats that had spontaneous withdrawal after $24 \mathrm{~h}$ or $15 \mathrm{~d}$, the activity of VTA DA neurons was similar to that of naive rats, and an acute injection of morphine failed to alter their activity. Our results indicate that VTA DA neurons show long-lasting tolerance to the acute effect of morphine after withdrawal. These findings show that VTA DA neural activity is unlikely to be a factor in the altered behavioral responses that occur with acute morphine or naltrexone administration after chronic opiate exposure.
\end{abstract}

Key words: addiction; withdrawal; opiates; ventral tegmental area; naltrexone; extracellular recording

\section{Introduction}

Dopamine (DA)-containing neurons originating in the ventral tegmental area (VTA) project primarily to the nucleus accumbens and the prefrontal cortex, forming the mesocorticolimbic system (Carr and Sesack, 2000; for review, see Onn et al. 2000; O'Donnell, 2003). All drugs of abuse influence DA-mediated neurotransmission by affecting directly or indirectly the activity of these cells (Spanagel and Weiss, 1999; Marinelli et al., 2003). These and other observations indicate that drug abuse is a DAdependent disorder in which the positive reinforcing value of the drug is mediated through the activation of the mesocorticolimbic DA system (Di Chiara, 1999). Adaptive changes in cellular and synaptic function in the mesocorticolimbic DA system after prolonged or repeated opiate administration have been shown (for review, see Williams et al., 2001). These adaptations are believed to play an important role in the development of physiological tolerance to and dependence on opiates and to contribute to additional changes underlying the complex neurobehavioral syndrome of opiate withdrawal (Nestler, 2001). This withdrawal

Received Nov. 25, 2005; revised April 6, 2006; accepted April 12, 2006.

This work was supported by Public Health Service Grant DA06214, grants from the University Victor Ségalen of Bordeaux 2, the "Centre National de la Recherche Scientifique Française," and the Mission "Interministérielle pour la Lutte contre les Toxicomanies" (MILDT;NMIL0401). We thank Dr. G. Harris for helpful comments on this manuscript.

Correspondence should be addressed to Dr. François Georges, Centre National de la Recherche Scientifique, Unité Mixte de Recherche 5541 "Interactions Neuronales et Comportements," BP28, Université Victor Segalen, Bordeaux 2, 146 rue Léo Saignat, 33076 Bordeaux Cedex, France. E-mail: francois.georges@bordeaux.inserm.fr.

D01:10.1523/JNEUROSCI.5032-05.2006

Copyright $\odot 2006$ Society for Neuroscience $\quad$ 0270-6474/06/265720-07\$15.00/0 syndrome has short-, long-, and very long-term features, including altered hedonic processing with increased drug reward and decreased rewarding properties of natural reinforcers long after acute withdrawal has ended (Harris and Aston-Jones, 2003).

The above observations indicate that opiate dependence or withdrawal may substantially alter the activity of VTA DA neurons to mediate these prolonged effects of exposure; however, although DA neurons have been studied extensively during opiate withdrawal (Diana et al., 1995, 1999), little is known about their activity during morphine dependence or their response to acute morphine during dependence. Here, we examined the effects of chronic morphine on VTA DA neuronal activity, as well as the response of these neurons to acute morphine during chronic morphine treatment or during morphine abstinence. Our results show that chronic morphine produces a prolonged tolerance in the activity of DA neurons to subsequent acute morphine injections, indicating that these neurons are unlikely to mediate many long-term effects of opiate dependence (e.g., craving and sensitization).

\section{Materials and Methods}

Animals. One hundred eighty-five Sprague Dawley rats (Taconic, Germantown, NY; Iffa-CREDO, Lyon, France; 200-225 g) were used. Rats were housed three or four per cage under controlled conditions $\left(22-23^{\circ} \mathrm{C} ; 40 \%\right.$ relative humidity; $12 \mathrm{~h}$ light/dark illumination cycle; lights on from 7 A.M. to 7 P.M.) and were allowed ad libitum access to commercial chow and tap water.

Chronic drug treatment. Two $75 \mathrm{mg}$ morphine pellets (provided by the 
National Institute on Drug Abuse, National Institutes of Health, Rockville, MD) were implanted subcutaneously under halothane anesthesia for the chronic morphine treatment. This procedure has been shown to produce the following results: (1) a consistent plasma morphine concentration beginning a few hours after the implantation of the pellets (Yoburn et al., 1985) and (2) a "full" withdrawal syndrome, including overt somatic signs after an acute injection of opiate antagonist (Frenois et al., 2002). Full behavioral dependence on morphine was achieved $24 \mathrm{~h}$ after implantation of the morphine pellets and remained relatively constant for $15 \mathrm{~d}$ (Gold et al., 1994). On the basis of these physiological and behavioral findings, we used the term "morphine dependent" (MD) to denote rats chronically implanted with two pellets of morphine. The drug-naive rats (naive) received placebo pellets containing the excipient without morphine $(n=12)$ or were not implanted $(n=52)$. Electrophysiological experiments in MD rats were performed $6 \mathrm{~d}$ after the implantation of morphine pellets $(n=88)$. Precipitated withdrawal (PW) was induced by intravenous injection of naltrexone hydrochloride (NAL) (Sigma, St. Louis, MO; $0.1 \mathrm{mg} / \mathrm{kg}$ dissolved in isotonic saline) in anesthetized MD rats placed in a stereotaxic frame. Electrophysiological experiments were performed within $1 \mathrm{~h}$ after NAL injection (1H-PW) $(n=10)$. Spontaneous withdrawal (SW) was induced by removing the pellets after $6 \mathrm{~d}$, and electrophysiological experiments were performed $24 \mathrm{~h}(24 \mathrm{H}-\mathrm{SW})(n=9)$ or $15 \mathrm{~d}(15 \mathrm{D}-\mathrm{SW})(n=14)$ after removal. To avoid exposing the other rats to the stress of a rat undergoing withdrawal, all rats in a cage received the same treatment.

Intravenous drug injection. The jugular vein was cannulated for intravenous administration of pharmacological agents. NAL $(0.1 \mathrm{mg} / \mathrm{kg})$ and morphine hydrochloride $(1 \mathrm{mg} / \mathrm{kg})$ were prepared in isotonic saline. The DA receptor agonist apomorphine (APO) $\left(0.1 \mathrm{mg} / \mathrm{kg}\right.$; Sigma) and the $\mathrm{D}_{2}$ DA receptor antagonist eticlopride $(0.1 \mathrm{mg} / \mathrm{kg}$; Sigma) were prepared in isotonic saline and used to pharmacologically characterize VTA DA neurons.

Surgery. Animals were initially anesthetized with 3\% halothane in air administered through a face mask. A tracheotomy was performed, and $2 \%$ halothane was delivered through a tracheal cannula via spontaneous respiration for surgical procedures. During recording experiments, the concentration of halothane was kept at $1.0-1.2 \%$. Animals were placed in a stereotaxic frame, and body temperature was maintained at $36-38^{\circ} \mathrm{C}$ with a thermistor-controlled electric heating pad. All incision points were infiltrated with a long-lasting anesthetic (sensorcaine, $0.5 \%$ ). The skull was exposed, and a hole was drilled above the VTA (5.3 mm caudal to bregma; $0.8 \mathrm{~mm}$ lateral to the midline).

VTA recordings. A glass micropipette (tip diameter, 2-3 $\mu \mathrm{m} ; 4-6 \mathrm{M} \Omega$ ) filled with a $2 \%$ Pontamine Sky Blue solution in $0.5 \mathrm{M}$ sodium acetate was lowered into the VTA. DA neurons were identified according to well established electrophysiological features (Guyenet and Aghajanian, 1978; Grace and Bunney, 1983, 1984; Tepper et al., 1984; Chiodo, 1988; Ungless et al., 2004). These included the following: (1) action potential (AP) with biphasic or triphasic waveform and a half AP width $>1.1 \mathrm{~ms}$ in duration; (2) single and/or burst spontaneous firing patterns (characterized by spike-amplitude decrement; and (3) inhibition of spontaneous activity by DA receptor agonists and subsequent reversal by DA receptor antagonists. Signals were amplified and filtered $(0.1-5 \mathrm{kHz}$ bandpass) with conventional electronics. Spikes of single neurons were discriminated, and digital pulses were sent to a computer for on-line data collection with a laboratory interface and software (CED 1401, Spike2; Cambridge Electronic Design, Cambridge, UK).

Histology. At the end of each recording experiment, the electrode placement was marked with an iontophoretic deposit of Pontamine Sky Blue dye ( $-20 \mu \mathrm{A}$; continuous current for 12-15 min). After the experimental procedures, the animals were deeply anesthetized with halothane $(5 \%)$ and decapitated. Brains were removed and snap-frozen in a solution of isopentane at $-70^{\circ} \mathrm{C}$.

Data analysis. Three parameters of VTA impulse activity were computed over $200 \mathrm{~s}$ epochs before and after drug administration: the basal firing rate, the proportion of spikes that occurred in bursts, and the regularity of firing. The onset of a burst was defined as the occurrence of two spikes with an interspike interval $<80 \mathrm{~ms}$ (Grace and Bunney, 1983). The percentage of spikes in bursts was calculated by dividing the number of spikes occurring in bursts (first spike of the burst not included) by the total number of spikes occurring in the same period of time. Variations of burst firing are reported as the percentage of spikes in bursts before the drug minus the percentage after the drug. We also evaluated the amount of bursting activity by calculating the burst-event frequency (number of burst events over time), the burst size (number of spikes within each burst), and the duration of each burst. Regularity of firing was measured with the coefficient of variation, i.e., the SD and mean value of instantaneous interspike intervals (Georges and Aston-Jones, 2002). Results are expressed throughout as mean \pm SEM. When two means were compared, the statistical significance of their difference was assessed by twotailed paired Student's $t$ tests. For multiple comparisons, values were subjected to a one-way ANOVA followed by post hoc Dunnett or Newman-Keuls tests.

\section{Results}

Data are reported for 520 histologically verified VTA neurons that were identified as DA neurons according to well established electrophysiological features (see Materials and Methods). All DA neurons reported here have an AP width of $\geq 1.1 \mathrm{~ms}$ (Ungless et al., 2004), and no difference for this criterion was observed among naive, dependent, or withdrawn rats (Fig. $1 B$ ) (ANOVA; $\left.F_{4,515}=2.140 ; p=0.075\right)$. The DA receptor agonist APO was administered for the last DA neuron recorded in each experiment $(0.1 \mathrm{mg} / \mathrm{kg}$, i.v.). As reported previously (Grace and Bunney, 1983 , 1984), this drug consistently inhibited spontaneous impulse activity of DA neurons within $30 \mathrm{~s}$ of injection. A subsequent injection of the $\mathrm{D}_{2}$ DA receptor antagonist eticlopride $(0.1$ $\mathrm{mg} / \mathrm{kg}$, i.v.) consistently restored impulse activity (Fig. 1C,D).

\section{The activity of VTA DA neurons is higher in morphine-dependent rats}

The basal firing rate of VTA DA neurons was higher in MD than in naive or withdrawn rats (Fig. $2 A$ ) (ANOVA; $F_{4,515}=12.42$; $p<0.0001)$. A typical recording of a fast-firing VTA DA neuron $(8.5 \mathrm{~Hz})$ is shown in Figure $1 C$. In contrast, the firing rates for the withdrawn groups did not differ from each other or from those in naive rats. The mean firing rate of VTA DA neurons in MD rats was $5.5 \pm 0.2 \mathrm{~Hz}$ compared with $3.9 \pm 0.2 \mathrm{~Hz}$ in naive, $4.5 \pm 0.2$ $\mathrm{Hz}$ in $1 \mathrm{H}-\mathrm{PW}, 4.1 \pm 0.2 \mathrm{~Hz}$ in $24 \mathrm{H}-\mathrm{SW}$, and $4.0 \pm 0.2 \mathrm{~Hz}$ in 15D-SW (Fig. 2A). A typical recording of a pharmacologically identified VTA DA neuron firing at $5.5 \mathrm{~Hz}$ in a $24 \mathrm{H}-\mathrm{SW}$ rat is shown in Figure $1 D$. The scatterplot in Figure $1 A$ reports the bursting activity as a function of firing rate for individual neurons. For clarity, only VTA DA neurons of naive and MD rats are shown on this graph. There were small but significant positive correlations between bursting activity (percentage spikes in bursts) and firing rate for VTA DA neurons in naive, MD, $1 \mathrm{H}$ PW, 24H-SW, and 15D-SW rats (naive, $r=0.10, p<0.0001$; $\mathrm{MD}, r=0.25, p<0.0001$; $1 \mathrm{H}-\mathrm{PW}, r=0.50, p<0.0001 ; 24 \mathrm{H}-$ SW, $r=0.31, p<0.0001$; 15D-SW, $r=0.16$, $p<0.0001$; Pearson's correlation). Firing rates for the five groups were normally distributed (Fig. 3) (range, 0.2-10.5 Hz), indicating similar neuronal populations in all groups of rats; however, the Gaussian curve was shifted $\sim 1.5 \mathrm{~Hz}$ to the right in MD compared with naive and withdrawn rats (Fig. $3 F$ ).

Morphine dependence increased the amount of burst events emitted over time (Fig. $2 B$ ) (ANOVA; $F_{4,527}=10.19 ; p<0.0001$ ) as well as the duration of the bursts (Fig. $2 E$ ) (ANOVA; $F_{4,527}=$ 17.50; $p<0.0001$ ). The mean burst-event frequency of VTA DA neurons in $\mathrm{MD}$ rats was $1.7 \pm 0.1 \mathrm{~Hz}$ compared with $1.2 \pm 0.1 \mathrm{~Hz}$ in naive, $1.2 \pm 0.1 \mathrm{~Hz}$ in $1 \mathrm{H}-\mathrm{PW}, 1.3 \pm 0.1 \mathrm{~Hz}$ in $24 \mathrm{H}-\mathrm{SW}$, and $1.0 \pm 0.1 \mathrm{~Hz}$ in $15 \mathrm{D}-\mathrm{SW}$ (Fig. $2 \mathrm{~B}$ ). The average burst duration of VTA DA neurons in MD rats was $108.6 \pm 2.0 \mathrm{~ms}$ compared with 
$89.3 \pm 2.8 \mathrm{~ms}$ in naive, $94.9 \pm 2.3 \mathrm{~ms}$ in $1 \mathrm{H}-\mathrm{PW}, 84.9 \pm 2.3 \mathrm{~ms}$ in $24 \mathrm{H}-\mathrm{SW}$, and $84.1 \pm 3.1 \mathrm{~ms}$ in $15 \mathrm{D}-\mathrm{SW}$ (Fig. $2 \mathrm{E}$ ). The means for spikes in bursts were similar in naive, $\mathrm{MD}$, and withdrawn rats (Fig. $2 C$ ) (ANOVA; $F_{4,515}=0.66 ; p=0.62$ ). The percentage of spikes occurring in bursts was $20.2 \pm 1.4 \%$ in naive, $19.7 \pm 1.4 \%$ in $\mathrm{MD}, 22.5 \pm 1.5 \%$ in $1 \mathrm{H}-\mathrm{PW}, 21.0 \pm 1.4 \%$ in $24 \mathrm{H}-\mathrm{SW}$, and $19.6 \pm 1.4 \%$ in $15 \mathrm{D}-\mathrm{SW}$ (Fig. 2C). The burst sizes (spikes per burst) were similar in naive, $\mathrm{MD}$, and withdrawn rats (Fig. $2 D)$ (ANOVA; $F_{4,527}=1.65 ; p=$ $0.16)$. The number of spikes per burst was $2.2 \pm 0.04$ in naive, $2.2 \pm 0.03$ in $\mathrm{MD}, 2.1 \pm$ 0.03 in $1 \mathrm{H}-\mathrm{PW}, 2.1 \pm 0.04$ in $24 \mathrm{H}-\mathrm{SW}$, and $2.1 \pm 0.02$ in $15 \mathrm{D}-\mathrm{SW}$ (Fig. $2 \mathrm{D}$ ).

The regularity of firing of VTA DA neurons was higher in $\mathrm{MD}$ than in naive or withdrawn rats (Fig. $2 F$ ) (ANOVA; $F_{4,515}=$ $2.7 ; p<0.03$ ). Regularity of firing was measured from the coefficient of variation (see Materials and Methods) and was $0.70 \pm$ 0.02 in naive, $0.63 \pm 0.02$ in $\mathrm{MD}, 0.72 \pm 0.02$ in $1 \mathrm{H}-\mathrm{PW}, 0.70 \pm 0.02$ in $24 \mathrm{H}-\mathrm{SW}$, and $0.70 \pm 0.02$ in $15 \mathrm{D}-\mathrm{SW}$ (Fig. $2 \mathrm{~F}$ ).

\section{Acute morphine did not modify the activity of VTA DA neurons in} morphine-dependent or withdrawn rats Administration of morphine $(1 \mathrm{mg} / \mathrm{kg}$, i.v.) to naive rats increased the impulse activity of VTA DA neurons to $\sim 40 \%$ and the burst firing to $\sim 80 \%$ of the pre-drug baseline within $3 \mathrm{~min}$ (Fig. 4A) (ANOVA; $\left.F_{5,66}=10.03 ; p<0.0001\right)$ (Table 1$)(p<$ 0.001 , Student's $t$ test for firing rate; $p<0.01$, Student's $t$ test for burst firing; $n=13$; typical example in Fig. $4 C$ ). This activation is maximal 3 min after the injection, and all cells returned to baseline activity 6-8 min after the injection (Fig. $4 \mathrm{~B}$ ).

In contrast to this activation in naive rats, intravenous injection of morphine to morphine-dependent or spontaneously withdrawn rats ( $24 \mathrm{~h}$ or $15 \mathrm{~d}$ after removal of morphine pellets) had no significant effect on the firing rate, burst firing, or regularity of firing of VTA DA neurons. Administration of morphine $(1 \mathrm{mg} / \mathrm{kg}$, i.v. $) 1 \mathrm{~h}$ after precipitating withdrawal with NAL $(0.1$ $\mathrm{mg} / \mathrm{kg}$, i.v.) elicited a small but significant decrease of firing rate $(-10 \%)$ and burst activity $(-8.5 \%)$ (Table 1$)(p<0.01$; Student's $t$ test for firing rate and burst firing; $n=6)$. This effect did not reach significance when the five groups were compared together in an ANOVA (Fig. 4A). Administration of saline had no effect on firing rate, burst firing, or regularity of firing of VTA DA neurons in naive, MD, 1H-PW, 24H-SW, or 15D-SW rats (all groups pooled together; ANOVA; $\left.F_{4,27}=0.31 ; p=0.870\right)$.

\section{Acute NAL normalized activity of VTA DA neurons in morphine-dependent rats}

Administration of NAL $(0.1 \mathrm{mg} / \mathrm{kg}$, i.v. $)$ precipitated a withdrawal syndrome in our anesthetized morphine-dependent rats. The following somatic signs were observed for each morphinepelleted rats injected with NAL: body shake, mastication, and rhinorrhea. These observations confirmed that our morphine treatment produced dependence.
B
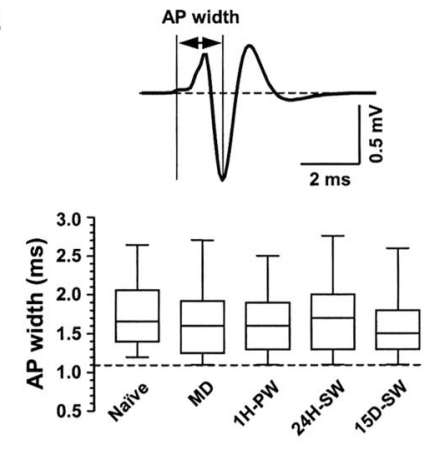

D

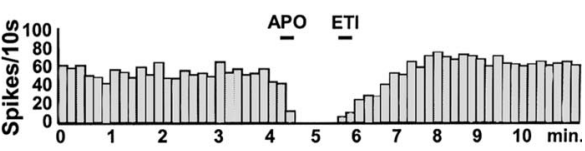

24H-SW DA neuron $(5.5 \mathrm{~Hz})$
Figure 1. Electrophysiological and pharmacological identification of VTA DA cells. A, Scatterplot showing the bursting activity percentage spikes in bursts (\%SIB)] as a function of firing rate of individual neurons from naive rats ( $n=64$ rats, 118 cells) and $\rightarrow$ $\overline{1 \mathrm{~s}}$ 胥

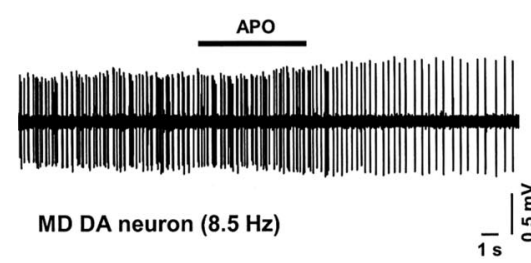
potential to the negative trough (top). An AP width $\leq 1.1 \mathrm{~ms}$ was used to exclude all non-DA neurons. AP widths were similar and (i. is designated by the line above the trace. $\boldsymbol{D}$, Firing rate histograms showing the firing activity in a typical VTA DA neuron $(5.5 \mathrm{~Hz}$ in a spontaneously withdrawn rat $24 \mathrm{~h}$ after removal of the pellet. Note the characteristic inhibition of spontaneous activity by APO $(0.1 \mathrm{mg} / \mathrm{kg}$, i.v. $)$ and subsequent reversal by eticlopride (ETI) $(0.1 \mathrm{mg} / \mathrm{kg}$, i.v. $)$.

Administration of NAL ( $0.1 \mathrm{mg} / \mathrm{kg}$, i.v. $)$ to morphinedependent rats decreased the tonic firing rate $(-40 \% ; n=10)$ (Fig. $4 D$ ) (ANOVA; $F_{5,64}=15.21 ; p<0.0001$ ) and the burst firing of VTA DA neurons $(-55 \% ; n=10)$ (Table 1$)(p<0.001$; Student's $t$ test) without affecting the regularity of firing. This reduction of activity was biphasic: (1) the first rapid inhibition was maximal $30 \mathrm{~s}$ after the injection and was followed by a return to baseline activity (Fig. $4 F$, trace); and (2) a second inhibition started $3 \mathrm{~min}$ after the injection and persisted for several hours [as reported previously (Georges and Aston-Jones, 2003)] (Fig. 4E). Analyses of impulse activity after NAL revealed that this second inhibition during withdrawal resulted only in a normalization of the firing rate to that of naive animals. Thus, the tonic firing rate of VTA DA neurons in naive rats $(4.5 \pm 0.2 \mathrm{~Hz})$ was similar to their firing rate in morphine-dependent rats after NAL $(4.2 \pm 0.6$ $\mathrm{Hz}$ ). NAL administered to naive or withdrawal rats had no significant effect on firing rate, burst firing, or regularity of firing of VTA DA neurons (Table 1).

\section{Discussion}

Here we confirmed that acute morphine in naive rats produced a marked increase in the firing of VTA DA neurons (Gysling and Wang, 1983; Matthews and German, 1984). Morphine dependence also increased the firing rate of VTA DA neurons compared with naive animals and produced a shift to the right in the firing rate distribution; however, our results also showed that, in dependent or withdrawal rats, an acute injection of morphine failed to increase the activity of DA neurons. We also confirmed that 
A

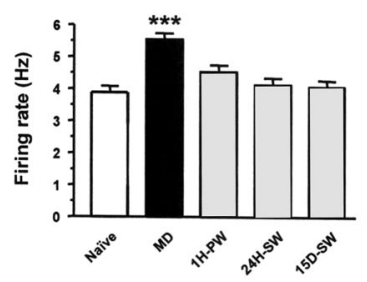

c

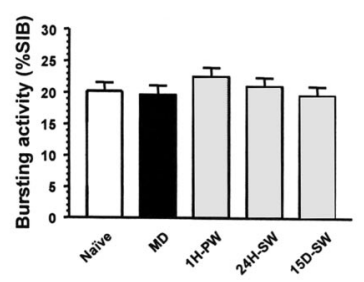

E

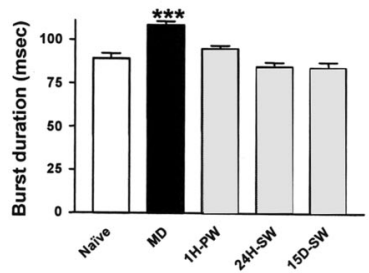

B

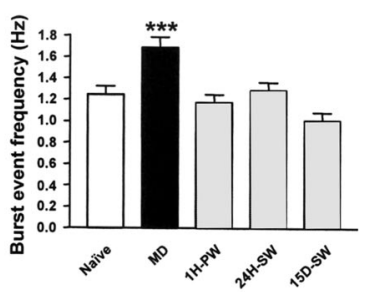

D

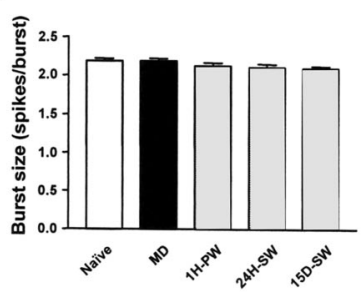

$\mathbf{F}$

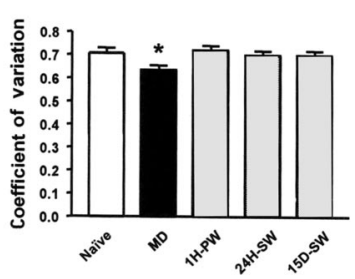

A

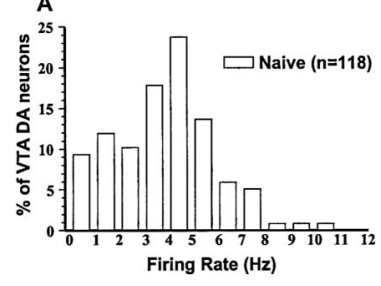

C

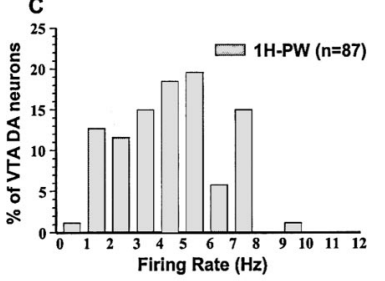

E

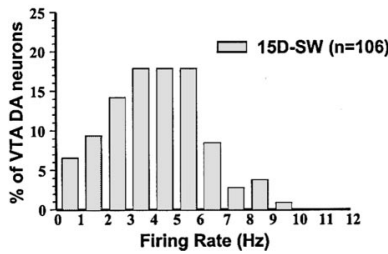

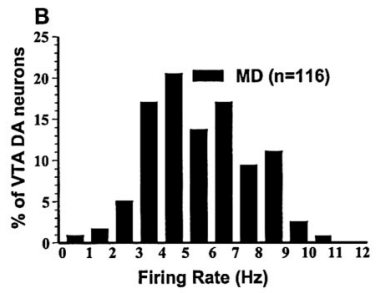

D
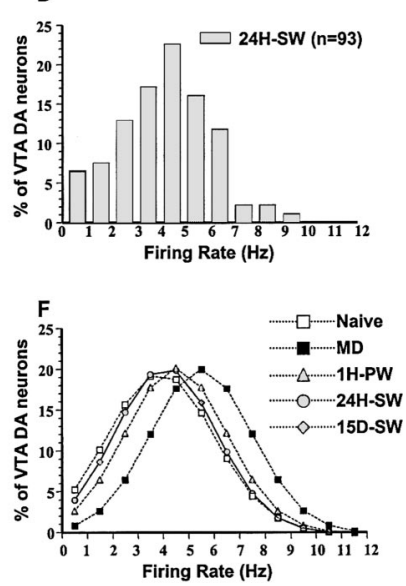

Figure 3. Analysis of the firing rate distributions of VTA DA neurons in naive rats ( $n=64$ rats, 118 cells), in MD rats ( $n=88$ rats, 116 cells), and in both withdrawal conditions [precipitated: $1 \mathrm{H}-\mathrm{PW}$ ( $n=10$ rats, 87 cells); spontaneous: $24 \mathrm{H}-\mathrm{SW}$ ( $n=9$ rats, 93 cells), and 15D-SW ( $n=14$ rats, 106 cells)]. $\boldsymbol{A}-\boldsymbol{E}$, Firing rate was measured for each cell and plotted as a proportion of total cells recorded. $\boldsymbol{F}$, Firing rates for the five groups of cells were normally distributed (range, $0.2-10.5 \mathrm{~Hz}$ ). Morphine dependence induced a shift to the right of the Gaussian curve of $\sim 1.5$ spikes per second, indicating hyperactivity of the VTA DA neuronal population.

release observed with microdialysis after acute morphine administration (Marinelli et al., 1998; Acquas et al., 1991; Pothos et al., 1991; Pontieri et al., 1995). Opiates interact with the DA system by suppressing GABA inhibitory input to DA neurons in the VTA (Johnson and North, 1992). Based on the increase of burst-firing after morphine, our results led us to hypothesize that, in addition to decreasing GABAergic inhibition of VTA DA neurons, morphine may increase glutamate-mediated excitatory inputs. Thus, it is tempting to propose that glutamatergic neurons innervating the VTA are involved, at least in part, in the activation of DA neurons during acute morphine administration. This idea is also consistent with recent findings that opiates (like other drugs of abuse) produce glutamate-mediated long-term potentiation in VTA DA neurons (Saal et al., 2003). Moreover, we recently demonstrated that synaptic plasticity in the VTA involving activation of glutamate receptors is necessary for both the acquisition and expression of morphine-conditioned place preference (Harris et al., 2004). Glutamate afferents to the VTA arise from three primary sources: the bed nucleus of the stria terminalis, the medial prefrontal cortex, and the pedunculopontine region (Fallon and Loughlin, 1995; Georges and Aston-Jones, 2002); this proposed elevated glutamate could originate in any of these inputs. It will be important in future studies to test this idea by examining the effect of morphine on VTA DA neuronal activity in the presence of glutamate antagonists or after specific inhibition of one of the three glutamatergic inputs to the VTA.

\section{Tolerance and hyperactivity in VTA DA neurons during} morphine dependence

An important and somewhat unexpected finding from the present study was that VTA DA neurons exhibited elevated im-

tance for the control of DA release in terminal areas (Gonon, 1988). Thus, our findings are consistent with the increase in DA 
pulse activity during morphine dependence. These data are consistent with a recent microdialysis study showing that continuous exposure to heroin elevates the basal level of DA in the nucleus accumbens (Leri et al., 2003). Notably, this change in tonic activity of VTA DA neurons during dependence coexisted with tolerance to the phasic excitatory effect of morphine. The observation of tolerance to the excitatory effects of morphine on VTA DA neurons during chronic morphine exposure is not surprising in light of a number of electrophysiological and biochemical findings indicating that morphine induces functional desensitization of opioid signaling (Sim et al., 1996; Williams et al., 2001) and that morphine-tolerant animals show adaptation in postreceptor signaling proteins (Nestler, 2001). Additional experiments are necessary to determine the mechanism by which VTA DA neuronal activity is elevated during chronic morphine treatment.

\section{Lack of withdrawal and morphine- induced sensitization in VTA DA neurons}

During acute withdrawal from morphine, we observed a drop in baseline activity of VTA DA neurons relative to their baseline activity measured during chronic morphine exposure; however, no differences were found among the baseline activities of VTA DA neurons from morphinewithdrawn compared with naive rats. These data are consistent with a recent microdialysis study showing that during acute withdrawal, basal extracellular DA levels in the nucleus accumbens were not different from those in vehicle-treated rats (Leri et al., 2003). Our data, however, contrast with the results of Diana et al. (1999), who found a lasting reduction in VTA DA activity after morphine withdrawal and an augmented magnitude of the response of these neurons to morphine after $14 \mathrm{~d}$ of withdrawal. These discrepancies with the present findings may result from differences in techniques used, such as the anesthetic procedures (halothane vs paralyzed, unanesthetized rat preparation), the routes of chronic morphine administration (pellet vs injection), the stress conditions, and/or the dose range of morphine studied (an acute challenge of morphine at $1 \mathrm{mg} / \mathrm{kg}$ vs cumulative doses up to $32 \mathrm{mg} / \mathrm{kg}$ ). The reasons for the discrepancy between these results and our own are not entirely clear, however, and further work will be necessary to test the possible, above-mentioned explanations.

On the basis of the acute actions of morphine in the mesolimbic DA pathway, it has been suggested that this system is also involved in morphine-induced behavioral sensitization (Kalivas and Stewart, 1991; Robinson and Berridge, 2000). During acute spontaneous withdrawal $(24 \mathrm{H}-\mathrm{SW})$ and protracted withdrawal (15D-SW), we observed a tolerance to the excitatory effect of morphine, as shown by the ineffectiveness of morphine to acti-
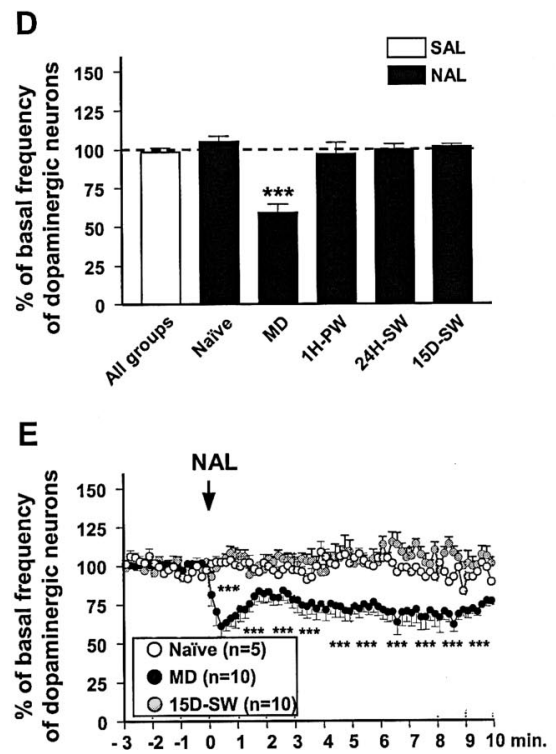

$\mathbf{F}$

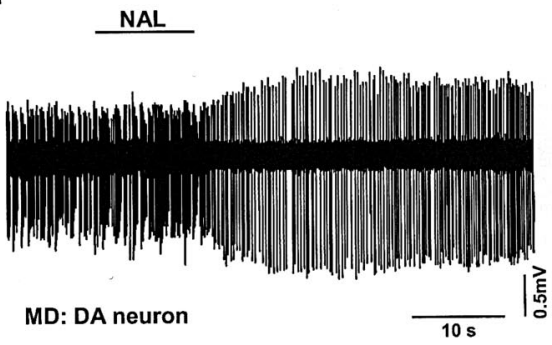

Figure 4. Overall effects of intravenous injections of morphine (MOR) $(1 \mathrm{mg} / \mathrm{kg})$ or NAL $(0.1 \mathrm{mg} / \mathrm{kg})$ on VTA DA neuronal spontaneous: $24 \mathrm{H}-\mathrm{SW}: \mathrm{MOR}, n=6$ rat, 6 cells; NAL, $n=8$ rats, 8 cells; 15D-SW:MOR, $n=8$ rats, 8 cells; NAL, $n=10$ rats, 10 cells). 列 (3) ${ }^{* *} p<0.001 ; * p<0.05$; ANOVA followed by Dunnett's test); however, in MD and withdrawn rats, acute morphine $n=10 ;{ }^{* *} p<0.001$; ANOVA followed by Dunnett's test). Note also that acute NAL had no effect on VTA DA activity in naive rats or in any withdrawal group. $\boldsymbol{F}$, Oscilloscope traces of impulses from a VTA DA neuron showing the typical decrease of firing activity after NAL injection in an MD rat. The NAL injection is designated by the line above the trace.

vate VTA DA neurons (Acquas and Di Chiara, 1992; Spanagel et al., 1993). Our results obtained during acute spontaneous withdrawal are consistent with previous neurochemical findings indicating that challenge with morphine had no effect on DA outflow on the first day of withdrawal (Acquas and Di Chiara, 1992); however, our results are not consistent with microdialysis studies in the nucleus accumbens, indicating a sensitization to morphine-induced mesolimbic DA release maintained for $5 \mathrm{~d}$ (Acquas and Di Chiara, 1992) or 4 weeks (Spanagel et al., 1993). In contrast to our study, these previous reports used daily escalating doses of morphine. One possible explanation for the discrepancy between our electrophysiological results and those neurochemical findings is that a drug of abuse may produce sensitization or tolerance depending on the temporal pattern of drug delivery (Kreek, 1997; Samaha et al., 2002). An alternative possibility is that morphine dependence and withdrawal lead to adaptive changes in key elements controlling DA levels in the synapse, and these changes could produce alterations in the 
Table 1. Overall effects of acute injections of morphine or naltrexone on VTA DA neuronal activity

\begin{tabular}{|c|c|c|c|c|c|c|c|}
\hline \multirow[b]{2}{*}{ Groups } & \multicolumn{3}{|c|}{200 s period preceding injection } & \multirow[b]{2}{*}{$\begin{array}{l}\text { Acute Injection } \\
(n)\end{array}$} & \multicolumn{3}{|c|}{200 s period following injection } \\
\hline & $\begin{array}{l}\text { Rate }(\mathrm{Hz}) \\
\text { Mean } \pm \text { SEM }\end{array}$ & $\begin{array}{l}\% \text { SIB } \\
\text { Mean } \pm \text { SEM }\end{array}$ & $\begin{array}{l}\text { VC } \\
\text { Mean } \pm \text { SEM }\end{array}$ & & $\begin{array}{l}\text { Rate }(\mathrm{Hz}) \\
\text { Mean } \pm \text { SEM }\end{array}$ & $\begin{array}{l}\% \text { SIB } \\
\text { Mean } \pm \text { SEM }\end{array}$ & $\begin{array}{l}\text { VC } \\
\text { Mean } \pm \text { SEM }\end{array}$ \\
\hline Naïve & $4.54 \pm 0.54$ & $16.63 \pm 4.16$ & $0.64 \pm 0.05$ & $\operatorname{MOR}(13)$ & $6.24 \pm 0.63^{* * *}$ & $30.18 \pm 4.88^{* *}$ & $0.71 \pm 0.06$ \\
\hline MD & $5.02 \pm 0.69$ & $7.62 \pm 3.43$ & $0.47 \pm 0.06$ & $\operatorname{MOR}(7)$ & $5.09 \pm 0.81$ & $8.12 \pm 2.75$ & $0.48 \pm 0.07$ \\
\hline 1H-PW & $5.51 \pm 0.50$ & $30.90 \pm 5.79$ & $0.78 \pm 0.10$ & $\operatorname{MOR}(6)$ & $4.98 \pm 0.46^{* *}$ & $26.41 \pm 4.98^{* *}$ & $0.76 \pm 0.11$ \\
\hline 24H-SW & $5.45 \pm 0.35$ & $24.20 \pm 1.99$ & $0.60 \pm 0.03$ & MOR (6) & $5.16 \pm 0.86$ & $23.14 \pm 1.55$ & $0.59 \pm 0.02$ \\
\hline 15D-SW & $4.68 \pm 0.76$ & $16.91 \pm 3.52$ & $0.55 \pm 0.03$ & MOR (8) & $4.98 \pm 0.78$ & $21.78 \pm 4.20$ & $0.64 \pm 0.07$ \\
\hline Naïve & $3.61 \pm 0.63$ & $15.95 \pm 5.50$ & $0.68 \pm 0.09$ & NAL (5) & $3.74 \pm 0.58$ & $16.23 \pm 6.50$ & $0.66 \pm 0.09$ \\
\hline MD & $7.07 \pm 0.88$ & $26.23 \pm 7.84$ & $0.61 \pm 0.11$ & NAL (10) & $4.20 \pm 0.60^{* * *}$ & $11.68 \pm 3.66^{* *}$ & $0.49 \pm 0.08$ \\
\hline 1H-PW & $3.93 \pm 0.69$ & $14.29 \pm 5.62$ & $0.70 \pm 0.09$ & NAL (5) & $3.68 \pm 0.44$ & $13.62 \pm 4.02$ & $0.71 \pm 0.09$ \\
\hline 24H-SW & $4.10 \pm 0.54$ & $19.53 \pm 3.09$ & $0.68 \pm 0.04$ & NAL (8) & $4.08 \pm 0.57$ & $18.80 \pm 3.94$ & $0.66 \pm 0.05$ \\
\hline 15D-SW & $5.46 \pm 1.06$ & $17.28 \pm 3.72$ & $0.58 \pm 0.05$ & NAL (10) & $5.61 \pm 1.17$ & $19.12 \pm 3.71$ & $0.59 \pm 0.04$ \\
\hline
\end{tabular}

Overall effects of intravenous injections of morphine (MOR) $(1 \mathrm{mg} / \mathrm{kg}$ ) or naltrexone (NAL) $(0.1 \mathrm{mg} / \mathrm{kg})$ on VTA DA neuronal firing rate, bursting activity (\% spikes in bursts, SIB) or regularity of firing (coefficient of variation) in drug-naive rats (Naive: for MOR, $n=13$ rat, 13 cells; for NAL, $n=5$ rats, 5 cells), morphine-dependent (MD, for MOR, $n=10$ rats, 10 cells; for NAL, $n=7$ rats, cells) rats, and in both withdrawal conditions (precipitated: $1 \mathrm{H}$-PW: for MOR, $n=6$ rats, 6 cells; for NAL, $n=5$ rats, 5 cells; spontaneous: $24 \mathrm{H}$-SW: for MOR, $n=6$ rats, 6 cells; for NAL, $n=8$ rats, 8 cells and 15D-SW: for MOR, $n=8$ rats, 8 cells; for NAL, $n=10$ rats, 10 cells). Note the lack of effect of acute morphone injection in rats during $24 \mathrm{~h}$ spontaneous withdrawal or during protracted withdrawal. ${ }^{* * *} p<0.001,{ }^{* *} p<0.01, t$ test for paired observations (pre-drug vs post-drug for the three electrophysiological parameters).

amount of DA released without altering the pattern of VTA neuronal activity. Two possible adaptive changes of this kind are the dopamine transporter (DAT) and the $\mathrm{D}_{2}$ dopamine autoreceptor (Spielewoy et al., 2000; Rouge-Pont et al., 2002). The DAT plays a central role in determining the duration and amplitude of DA action by rapidly recapturing extracellular DA into presynaptic terminals after release (Benoit-Marand et al., 2000). Moreover, voltammetry studies have demonstrated that morphine in mice with a genetic disruption of the DAT produced a dramatic supernormal increase in the level of extracellular DA (Spielewoy et al., 2000). Thus, adaptive changes at the level of the DAT could produce the long-lasting changes in morphine-induced mesolimbic dopamine release observed (Spanagel et al., 1993) without altering the activity of VTA DA neurons (Budygin et al., 2004). This hypothesis is indirectly supported by studies showing that a history of opiate dependence can enhance the reinforcing effects of cocaine in a conditioned place preference (Lett, 1989; Leri et al., 2003).

The $\mathrm{D}_{2}$ dopamine autoreceptor is another potential target for neuroadaptive changes during morphine dependence that could produce elevated DA release without changing DA neural activity. Microdialysis studies have shown that the increase in extracellular DA induced by morphine was higher in mice lacking $\mathrm{D}_{2}$ dopamine receptors than in wild-type animals (Rouge-Pont et al., 2002). Thus, the development of DA-dependent behavioral sensitization (Kalivas and Stewart, 1991), together with our results and other neurochemical studies (Acquas and Di Chiara, 1992; Spanagel et al., 1993), suggests that alterations in the DAT and/or the $\mathrm{D}_{2}$ dopamine autoreceptor could play a role in the modulation of DA release in response to morphine reexposure after a period of abstinence without a change in the firing rate of DA neurons.

In summary, morphine increases VTA DA neuronal discharge and bursting activity in naive animals and triggers adaptive changes such as tolerance and hyperactivity in VTA DA neurons when administered chronically. Acute or protracted withdrawal causes the basal tonic activity of these DA neurons to return to the normal baseline of naive rats but also to become unresponsive to acutely administered morphine. Thus, long-term adaptations in VTA DA neurons induced by chronic opioid treatment are expressed in the absence of the drug and indicate long-lasting changes in the functioning of the VTA DA system.

\section{References}

Acquas E, Di Chiara G (1992) Depression of mesolimbic dopamine transmission and sensitization to morphine during opiate abstinence. J Neurochem 58:1620-1625.

Acquas E, Carboni E, Di Chiara G (1991) Profound depression of mesolimbic dopamine release after morphine withdrawal in dependent rats. Eur J Pharmacol 193:133-134.

Benoit-Marand M, Jaber M, Gonon F (2000) Release and elimination of dopamine in vivo in mice lacking the dopamine transporter: functional consequences. Eur J Neurosci 12:2985-2992.

Budygin EA, Brodie MS, Sotnikova TD, Mateo Y, John CE, Cyr M, Gainetdinov RR, Jones SR (2004) Dissociation of rewarding and dopamine transporter-mediated properties of amphetamine. Proc Natl Acad Sci USA 101:7781-7786.

Carr DB, Sesack SR (2000) Projections from the rat prefrontal cortex to the ventral tegmental area: target specificity in the synaptic associations with mesoaccumbens and mesocortical neurons. J Neurosci 20:3864-3873.

Chiodo LA (1988) Dopamine-containing neurons in the mammalian central nervous system: electrophysiology and pharmacology. Neurosci Biobehav Rev 12:49-91.

Diana M, Pistis M, Muntoni A, Gessa G (1995) Profound decrease of mesolimbic dopaminergic neuronal activity in morphine withdrawn rats. J Pharmacol Exp Ther 272:781-785.

Diana M, Muntoni AL, Pistis M, Melis M, Gessa GL (1999) Lasting reduction in mesolimbic dopamine neuronal activity after morphine withdrawal. Eur J Neurosci 11:1037-1041.

Di Chiara G (1999) Drug addiction as dopamine-dependent associative learning disorder. Eur J Pharmacol 375:13-30.

Fallon JH, Loughlin SE (1995) The rat nervous system: substantia nigra (Paxinos G, ed), pp 215-237. New York: Academic.

Frenois F, Cador M, Caille S, Stinus L, Le Moine C (2002) Neural correlates of the motivational and somatic components of naloxone-precipitated morphine withdrawal. Eur J Neurosci 16:1377-1389.

Georges F, Aston-Jones G (2002) Activation of ventral tegmental area cells by the bed nucleus of the stria terminalis: a novel excitatory amino acid input to midbrain dopamine neurons. J Neurosci 22:5173-5187.

Georges F, Aston-Jones G (2003) Prolonged activation of mesolimbic dopaminergic neurons by morphine withdrawal following clonidine: participation of imidazoline and norepinephrine receptors. Neuropsychopharmacology 28:1140-1149.

German DC, Dalsass M, Kiser RS (1980) Electrophysiological examination of the ventral tegmental (A10) area in the rat. Brain Res 181:191-197.

Gold LH, Stinus L, Inturrisi CE, Koob GF (1994) Prolonged tolerance, dependence and abstinence following subcutaneous morphine pellet implantation in the rat. Eur J Pharmacol 253:45-51.

Gonon FG (1988) Nonlinear relationship between impulse flow and dopamine released by rat midbrain dopaminergic neurons as studied by in vivo electrochemistry. Neuroscience 24:19-28.

Grace AA, Bunney BS (1983) Intracellular and extracellular electrophysiol- 
ogy of nigral dopaminergic neurons: identification and characterization. Neuroscience 10:301-315.

Grace AA, Bunney BS (1984) The control of firing pattern in nigral dopamine neurons: single spike firing. J Neurosci 4:2866-2876.

Guyenet PG, Aghajanian GK (1978) Antidromic identification of dopaminergic and other output neurons of the rat substantia nigra. Brain Res 150:69-84.

Gysling K, Wang RY (1983) Morphine-induced activation of A10 dopamine neurons in the rat. Brain Res 277:119-127.

Harris GC, Aston-Jones G (2003) Altered motivation and learning following opiate withdrawal: evidence for prolonged dysregulation of reward processing. Neuropsychopharmacology 28:865-871.

Harris GC, Wimmer M, Byrne R, Aston-Jones G (2004) Glutamateassociated plasticity in the ventral tegmental area is necessary for conditioning environmental stimuli with morphine. Neuroscience 129:841-847.

Johnson SW, North RA (1992) Opioids excite dopamine neurons by hyperpolarization of local interneurons. J Neurosci 12:483-488.

Kalivas PW, Stewart J (1991) Dopamine transmission in the initiation and expression of drug- and stress-induced sensitization of motor activity. Brain Res Brain Res Rev 16:223-244.

Kreek MJ (1997) Opiate and cocaine addictions: challenge for pharmacotherapies. Pharmacol Biochem Behav 57:551-569.

Leri F, Flores J, Rajabi H, Stewart J (2003) Effects of cocaine in rats exposed to heroin. Neuropsychopharmacology 28:2102-2116.

Lett BT (1989) Repeated exposures intensify rather than diminish the rewarding effects of amphetamine, morphine, and cocaine. Psychopharmacology 98:357-362.

Marinelli M, Aouizerate B, Barrot M, Le Moal M, Piazza PV (1998) Dopamine-dependent responses to morphine depend on glucocorticoid receptors. Proc Natl Acad Sci USA 95:7742-7747.

Marinelli M, Cooper DC, Baker LK, White FJ (2003) Impulse activity of midbrain dopamine neurons modulates drug-seeking behavior. Psychopharmacology 168:84-98.

Matthews RT, German DC (1984) Electrophysiological evidence for excitation of rat ventral tegmental area dopamine neurons by morphine. Neuroscience 11:617-625.

Nestler EJ (2001) Molecular basis of long-term plasticity underlying addiction. Nat Rev Neurosci 2:119-128.

O’Donnell P (2003) Dopamine gating of forebrain neural ensembles. Eur J Neurosci 17:429-435.

Onn SP, West AR, Grace AA (2000) Dopamine-mediated regulation of striatal neuronal and network interactions. Trends Neurosci 23:S48-56.
Pontieri FE, Tanda G, Di Chiara G (1995) Intravenous cocaine, morphine, and amphetamine preferentially increase extracellular dopamine in the "shell" as compared with the "core" of the rat nucleus accumbens. Proc Natl Acad Sci USA 92:12304-12308.

Pothos E, Rada P, Mark GP, Hoebel BG (1991) Dopamine microdialysis in the nucleus accumbens during acute and chronic morphine, naloxoneprecipitated withdrawal and clonidine treatment. Brain Res 566:348-350.

Robinson TE, Berridge KC (2000) The psychology and neurobiology of addiction: an incentive-sensitization view. Addiction 95:S91-117.

Rouge-Pont F, Usiello A, Benoit-Marand M, Gonon F, Piazza PV, Borrelli E (2002) Changes in extracellular dopamine induced by morphine and cocaine: crucial control by $\mathrm{D}_{2}$ receptors. J Neurosci 22:3293-3301.

Saal D, Dong Y, Bonci A, Malenka RC (2003) Drugs of abuse and stress trigger a common synaptic adaptation in dopamine neurons. Neuron 37:577-582.

Samaha AN, Li Y, Robinson TE (2002) The rate of intravenous cocaine administration determines susceptibility to sensitization. J Neurosci 22:3244-3250

Sim LJ, Selley DE, Dworkin SI, Childers SR (1996) Effects of chronic morphine administration on $\mu$ opioid receptor-stimulated $\left[{ }^{35} \mathrm{~S}\right] \mathrm{GTP} \gamma \mathrm{S}$ autoradiography in rat brain. J Neurosci 16:2684-2692.

Spanagel R, Weiss F (1999) The dopamine hypothesis of reward: past and current status. Trends Neurosci 22:521-527.

Spanagel R, Almeida OF, Shippenberg TS (1993) Long lasting changes in morphine-induced mesolimbic dopamine release after chronic morphine exposure. Synapse 14:243-245.

Spielewoy C, Gonon F, Roubert C, Fauchey V, Jaber M, Caron MG, Roques BP, Hamon M, Betancur C, Maldonado R, Giros B (2000) Increased rewarding properties of morphine in dopamine-transporter knockout mice. Eur J Neurosci 12:1827-1837.

Tepper JM, Young SJ, Groves PM (1984) Autoreceptor-mediated changes in dopaminergic terminal excitability: effects of increases in impulse flow. Brain Res 309:309-316.

Ungless MA, Magill PJ, Bolam JP (2004) Uniform inhibition of dopamine neurons in the ventral tegmental area by aversive stimuli. Science 303:2040-2042.

Williams JT, Christie MJ, Manzoni O (2001) Cellular and synaptic adaptations mediating opioid dependence. Physiol Rev 81:299-343.

Yoburn BC, Chen J, Huang T, Inturrisi CE (1985) Pharmacokinetics and pharmacodynamics of subcutaneous morphine pellets in the rat. J Pharmacol Exp Ther 235:282-286. 